\title{
Avoidance of Apoptosis in Alzheimer's Disease
}

\author{
Akihiko Nunomura and Shigeru Chiba \\ Department of Psychiatry and Neurology, \\ Asahikawa Medical College, Asahikawa \\ 078-8510, Japan
}

Internucleosomal DNA fragmentation, which is a well-known feature of apoptosis but not an absolute criterion for identifying apoptosis (1), has often been observed in the brain tissue of Alzheimer's disease (AD). However, classical apoptotic morphology such as nuclear condensation, membrane blebbing and apoptotic bodies are seldom seen in AD brain. In this issue of Journal of Alzheimer's Disease, Velez-Pardo et al. have reported the DNA fragmentation using terminal dUTP labeling (TUNEL) in postmortem brains of familial AD with presenilin-1 [E280A] mutation. Importantly, no classical apoptotic morphology has been observed also in the brains of presenilin-1 familial AD. Furthermore, VelezPardo et al. have shown that there is no obvious correlation between DNA fragmentation and the severity of amyloid deposition as well as between DNA fragmentation and the severity of neurofibrillary tangle formation.

An apoptotic pathway only takes several hours or at most a few days for completion. In the development of the lateral motor column of the chick embryo, 8,000 cells out of 20,000 cells die, i.e. loss of $40 \%$ of the population occurs within 3 days (2). The fact that only $5 \%$ of the population in the lateral motor column is undergoing apoptosis at any particular time in this period (2) indicates that apoptotic pathway requires about 10 hours for completion. In a striking contrast with the physiologically programmed cell death, loss of $40 \%$ of the population occurs $(3,000$ neurons out of 7,000 neurons per 50 micron-thick section are lost) within 10 years in the temporal cortex neurons of $\mathrm{AD}$ (3). If we suppose that $20-40 \%$ of neurons of the temporal cortex are undergoing degeneration at any given time in the course of $\mathrm{AD}$, an individual neuron in the temporal cortex of $\mathrm{AD}$ requires $5-10$ years to die. Indeed, we can observe neurons displaying many of the features of apoptosis in AD. This fact argues that neurons in $\mathrm{AD}$ have mounted an effective defense to apoptotic death (an avoidance of apoptosis) rather than actual completion of apoptosis $(4,5)$.

It is noteworthy that nucleic acid oxidation occurs widely in vulnerable neuronal populations in AD (6) and oxidative damage can directly cause DNA fragmentation (7). Therefore, DNA damage possibly resulting from oxidative stress involves vulnerable neurons in $\mathrm{AD}$ beyond the distribution of amyloid deposition or neurofibrillary tangles, which may be related to neuronal cell death occurring independently of the classical AD pathology (3).

\section{REFERENCES}

1. Collins RJ, Harmon BV, Gobe GC, Kerr JFR, Internucleosomal DNA cleavage should not be the sole criterion for identifying apoptosis, Int J Radiat Biol 61 (1992) 451-453.

2. Hamburger V, Cell death in the development of the lateral motor column of the chick embryo, $\mathrm{J}$ Comp Neurol 160 (1975) 535-546.

3. Gomez-Isla T, Hollister R, West H, Mui S, Growdon JH, Petersen RC, Parisi JE, Hyman BT, Neuronal loss correlates with but exceeds neurofibrillary tangles in Alzheimer's disease, Ann Neurol 41 (1997) 17-24. 
4. Perry G, Nunomura A, Smith MA, A suicide note from Alzheimer disease neurons? Nature Med 8 (1998) 897-898.

5. Perry G, Nunomura A, Lucassen P, Lassmann H, Smith MA, Apoptosis and Alzheimer's disease, Science 282 (1998) 1268-1269.

6. Nunomura A, Perry G, Pappolla MA, Wade R, Hirai K, Chiba S, Smith MA, RNA oxidation is a prominent feature of vulnerable neurons in Alzheimer's disease, J Neurosci 19 (1999) 1959-1964.

7. Tsang SY, Tam SC, Bremner I, Burkitt MJ, Copper-1, 10-phenanthroline induces internucleosomal DNA fragmentation in HepG2 cells, resulting from direct oxidation by the hydroxyl radical, Biochem J 317 (1996) 13-16. 